\title{
Valorização do contato pele a pele entre mãe e filho na primeira hora de vida: contribuições da enfermagem
}

\author{
Valuing skin-to-skin contact between mother and child in the first hour of life: nursing \\ contributions
}

Valorar el contacto piel entre madre e hijo en la primera hora de vida: aportes de enfermeira

\section{Resumo}

O contato pele a pele entre mãe e filho de forma imediata, para incentivar o aleitamento materno precoce, ações como o contato físico muito precoce, estabelecido ainda na sala de parto, bem como o incentivo da equipe multiprofissional são de extrema relevância. Compreende-se, portanto, que os cuidados maternos formam a base da vida emocional e de relacionamento do recém-nascido. Este estudo tem como objetivo entender através da literatura científica a contribuição da equipe de enfermagem na condução do contato pele a pele na primeira hora de vida. Optou-se pela pesquisa estudo exploratório, descritivo do tipo revisão bibliográfica na busca de artigos científicos, utilizando-se as bases de dados da Biblioteca Virtual em Saúde e Google Acadêmico, no período de 2015 a 2020. A partir da busca e análise de artigos científicos, emergiram-se duas categorias: Contribuições da equipe de enfermagem para a realização do contato pele a pele e o contato pele a pele e a importância para a mãe e o bebê. Conclui-se que é 
de extrema importância este contato da pele do bebe com a mãe logo após o nascimento, sendo a enfermagem inserida de forma fundamental para favorecer esta aproximação.

Palavras-chave: Enfermagem; Contato pele a pele; Recém-nascido.

\begin{abstract}
Immediate skin-to-skin contact between mother and child, to encourage early breastfeeding, actions such as very early physical contact, established even in the delivery room, as well as the encouragement of the multidisciplinary team are extremely relevant. It is understood, therefore, that maternal care forms the basis of the newborn's emotional and relationship life. This study aims to understand, through the scientific literature, the contribution of the nursing team in conducting skin-to-skin contact in the first hour of life. An exploratory, descriptive study of the bibliographic review type was chosen in the search for scientific articles, using the databases of the Virtual Health Library and Academic Google, in the period from 2015 to 2020. From the search and analysis of articles scientific, two categories emerged: Contributions of the nursing team to the realization of skin-to-skin contact and skin-to-skin contact and the importance for the mother and the baby. It is concluded that this contact between the baby's skin and the mother right after birth is extremely important, with nursing being fundamentally inserted to favor this approach.
\end{abstract}

Keywords: Nursing; Skin-to-skin contact; Newborn.

\title{
Resumen
}

El contacto piel a piel inmediato entre madre e hijo, para incentivar la lactancia materna temprana, acciones como el contacto físico muy temprano, establecido incluso en la sala de partos, así como el estímulo del equipo multidisciplinario son de suma relevancia. Se entiende, por tanto, que el cuidado materno constituye la base de la vida emocional y relacional del recién nacido. Este estudio tiene como objetivo comprender, a través de la literatura científica, la contribución del equipo de enfermería en la realización del contacto piel con piel en la primera hora de vida. Se eligió un estudio exploratorio, descriptivo del tipo revisión bibliográfica en la búsqueda de artículos científicos, utilizando las bases de datos de la Biblioteca Virtual en Salud y Google Academic, en el período de 2015 a 2020. A partir de la búsqueda y análisis de artículos científicos, dos categorías Surgió: Contribuciones del equipo de enfermería a la realización del contacto piel a piel y al contacto piel a piel y la importancia para la madre y el bebé. Se concluye que este contacto entre la piel del bebé y la madre inmediatamente después del nacimiento es de suma importancia, siendo fundamentalmente insertada la lactancia para favorecer este abordaje.

Palabras clave: Enfermería; Contacto piel a piel; Recién nacido.

\section{Introdução}

O contato precoce entre mãe e bebê deve ser valorizado pois alcança vários objetivos, dentre eles a capacidade para amar do ser humano que se dá logo após o nascimento, sendo este apontado como um período curto que trazem benefícios em longo prazo. A valorização do primeiro contato tem grande importância para a mulher, uma vez que ficará marcado por toda a sua vida, onde vai destacar sua prática de aleitamento, devendo ser efetivado de maneira a gerar experiências positivas (Leite et al., 2016).

A normatização proposta pela Organização Mundial de Saúde (OMS) afirma que é de suma importância o contato pele a pele entre mãe e filho de forma imediata, para incentivar o aleitamento materno precoce. A aproximação entre mãe e filho é preconizada, mostrando os benefícios dessa aproximação para aumentar a duração da amamentação, tirando proveito do fato que na primeira hora de vida que o bebê permanece em estado de alerta (OMS/UNICEF, 2015).

A portaria, que foi publicada no Diário Oficial da União (2014), recomenda ainda que o aleitamento materno na primeira hora de vida do bebê, exceto em casos de mães HIV ou HTLV positivas. O texto propõe também que o exame físico, pesagem e vacinação do recém-nascido, entre outros procedimentos, sejam feitos apenas depois da sua primeira hora de vida.

Outra proposta da portaria é quanto ao clampeamento do cordão umbilical do recém-nascido, que deve ser feito após cessadas as pulsações do recém-nascido (aproximadamente de 1 a 3 minutos), exceto em casos de mães isoimunizadas ou HIV / HTLV positivas, em que o clampeamento deve continuar sendo feito de imediato.

A humanização na atenção à saúde da mulher implica a promoção, o reconhecimento e o respeito aos direitos humanos, incluindo os eventos da gestação, parto e nascimento, de forma a colocar a mulher como protagonista destes eventos. A gestação e o parto não são apenas eventos biológicos, mas também sociais, uma vez que envolvem família e comunidade, 
cuja protagonista deve ser a mulher. Nesse cenário, os profissionais de saúde possuem um papel importante, porém como coadjuvantes: a equipe de saúde deve estar ao lado da mulher para prestar apoio, ajudar a minimizar a dor, orientar e saber reconhecer momentos críticos (Brasil, 2015).

Durante a jornada acadêmica das autoras, foi vivenciado uma evidente necessidade de ser perpetuado o contato pele a pele, com iniciativa a partir dos profissionais de saúde, que muitas vezes não desenvolvem esta prática, mesmo havendo possibilidades, ambiente e tempo necessário para exercer este momento tão importante para a mãe e seu bebê.

Cabe salientar, que no parto cesariana, esta prática não foi perpetuada, sendo interessante esta observação quando o momento foi comparado ao parto natural assistido por enfermeiro, onde a prática do contato pele a pele foi executada.

É de suma importância trabalhar na qualificação dos recursos humanos é ponto chave para melhorar e humanizar a assistência ao parto, garantindo bem-estar físico e emocional, compartilhando informações sempre que necessário, permitindo a presença de acompanhante na sala de parto, se for da vontade da mulher, respeitando a privacidade da mesma, permitindo o contato imediato da mãe com o bebê, e sobretudo proporcionando um ambiente acolhedor e uma assistência qualificada, baseada em princípios éticos e científicos (Almeida, 2015).

Considera-se essenciais o cuidado e o conforto da parturiente durante o trabalho de parto, no qual os recursos utilizados para sua garantia devam considerar riscos e benefícios além do desejo da parturiente. Alguns métodos não farmacológicos são utilizados e estes constituem um conjunto de técnicas para alívio da dor, que envolve conhecimento da prática de cuidados de enfermagem em centro obstétrico (Rocha et al., 2015).

Diante de todo exposto, levantou-se as seguintes questões norteadoras desta pesquisa: Qual o papel do enfermeiro na condução do contato pele a pele na primeira hora de vida do recém-nascido? De que forma o contato pele a pele contribui para o binômio mãe e filho?

Este estudo contribuirá para a aplicação da relação complexa e única, que evolve a mãe e o bebê, nos aproximando da necessidade de aprofundarmos nossa compreensão acerca desse período, em uma tentativa de aproximação e compreensão de aspectos presentes no início da vida.

Ações como o contato físico muito precoce, estabelecido ainda na sala de parto, bem como o incentivo da equipe multiprofissional são de extrema relevância. Compreende-se, portanto, que os cuidados maternos formam a base da vida emocional e de relacionamento do RN. Assim, é necessária a atuação da equipe de modo humanizado para que as ações possam ser desenvolvidas para a consolidação do vínculo (Fassarella et al., 2018).

Este estudo tem como objetivos específicos apontar a contribuição da equipe de enfermagem para o primeiro contato pele a pele do bebê e discutir de que forma o contato pele a pele favorece o binômio mãe e bebê.

\section{Metodologia}

Trata-se de um estudo exploratório, descritivo do tipo revisão bibliográfica na busca de artigos científicos. Pesquisa é um procedimento racional, sistemático, que tem por objetivo buscar respostas aos problemas que são propostos, é uma indagação minuciosa ou exame crítico e exaustivo na procura de fatos e princípios; uma diligente busca para averiguar algo. Pesquisar não é apenas procurar a verdade; é encontrar respostas para questões propostas, utilizando métodos científicos (Marconi; Lakatos, 2019).

A pesquisa científica é desenvolvida mediante o concurso dos conhecimentos disponíveis e a utilização cuidadosa de métodos e técnicas de investigação científica. Na realidade, a pesquisa desenvolve-se ao longo de um processo que envolve inúmeras fases, desde adequada formulação do problema até a satisfatória apresentação dos resultados (Gil, 2019). 
A busca de artigos foi realizada na base de dados BDENF, LILACS e SCIELO, havendo necessidade de utilizar a ferramenta o Google Acadêmico com a coleta de dados durante os meses de julho à setembro, para melhor suporte para a pesquisa. Para a seleção foram utilizados os seguintes requisitos de inclusão: Recorte temporal no período de 2015 a 2020 , em língua portuguesa, textos completos, que atendam a temática, com as palavras-chave: Enfermagem; contato pele a pele e recém-nascido.

Para a busca dos trabalhos foram utilizados os seguintes critérios para exclusão: Artigos com publicações superiores ao recorte temporal de 5 anos, em língua estrangeira, textos incompletos e resumos.

\section{Resultados e Discussão}

Após a associação com a utilização de palavras-chave, foram encontrados 8.070 artigos, excluídos 7.987 e selecionados 78 artigos. Com a leitura dos artigos, após o critério de exclusão foram selecionados 20 artigos que abrangessem o tema para a discussão.

Tabela 1. Analise da busca:

\begin{tabular}{|c|c|c|}
\hline Palavras-Chave & Sites pesquisados & Artigos pós seleção de critérios \\
\hline \multirow{4}{*}{$\begin{array}{c}\text { Enfermagem AND } \\
\text { Contato pele a pele AND } \\
\text { Recém-nascido }\end{array}$} & BDENF - 13 artigos & 6 \\
\hline & LILACS -46 artigos & 5 \\
\hline & SCIELO - 12 artigos & 3 \\
\hline & $\begin{array}{c}\text { GOOGLE ACADÊMICO - } 7 \\
\text { artigos }\end{array}$ & 6 \\
\hline \multicolumn{2}{|c|}{ TOTAL } & 20 \\
\hline
\end{tabular}

Fonte: Autores.

Quadro 1- Síntese dos artigos incluídos na Revisão Bibliográfica da pesquisa.

\begin{tabular}{|c|c|c|c|c|c|}
\hline $\begin{array}{l}\text { BASE DE } \\
\text { DADOS }\end{array}$ & TEMA & $\begin{array}{l}\text { FONTE/ } \\
\text { ANO }\end{array}$ & AUTOR & OBJETIVOS & RESULTADOS/CONCLUSÃO \\
\hline $\begin{array}{l}\text { GOOGLE } \\
\text { ACADÊMICO }\end{array}$ & 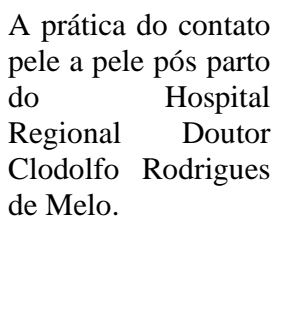 & $\begin{array}{l}\text { Revista } \\
\text { Baiana De } \\
\text { Enfermage } \\
\text { m2015, . }\end{array}$ & $\begin{array}{l}\text { Monika } \\
\text { Cavalcante } \\
\text { Silva. }\end{array}$ & $\begin{array}{l}\text { Centra-se em descrever a } \\
\text { implantação do método } \\
\text { do contato pele a pele } \\
\text { após o nascimento na } \\
\text { primeira hora de vida. }\end{array}$ & $\begin{array}{l}\text { O presente estudo contribuiu para } \\
\text { que os profissionais de saúde } \\
\text { assumam um papel preponderante } \\
\text { para a realização deste contato, } \\
\text { podendo estimular facilitar mesmo. } \\
\text { É importante oferecer tempo } \\
\text { díade/tríade para este contato, } \\
\text { proporcionar um ambiente } \\
\text { tranquilo. }\end{array}$ \\
\hline $\begin{array}{l}\text { GOOGLE } \\
\text { ACADÊMICO }\end{array}$ & $\begin{array}{l}\text { Contribuições da } \\
\text { enfermagem para o } \\
\text { contato pele a pele } \\
\text { entre o binômio } \\
\text { mãe-filho. }\end{array}$ & $\begin{array}{l}\text { Rev. Bras. } \\
\text { Enferm, } 20 \\
15 .\end{array}$ & $\begin{array}{l}\text { Renata Souza } \\
\text { Aguiar. }\end{array}$ & $\begin{array}{l}\text { Fortalecer as práticas do } \\
\text { contato pele a pele } \\
\text { precoce entre mãe-filho } \\
\text { e as contribuições } \\
\text { positivas da equipe de } \\
\text { enfermagem. }\end{array}$ & $\begin{array}{l}\text { Este estudo visa a promover } \\
\text { mudanças na equipe de enfermagem } \\
\text { em relação às contribuições para } \\
\text { proporcionar e executar. }\end{array}$ \\
\hline $\begin{array}{l}\text { GOOGLE } \\
\text { ACADÊMICO }\end{array}$ & $\begin{array}{l}\text { Fortalecendo o } \\
\text { vínculo mãe-filho } \\
\text { por meio do contato } \\
\text { pele a pele: Uma } \\
\text { intervenção junto à }\end{array}$ & $\begin{array}{l}\text { Rev. Bras. } \\
\text { Saúde } \\
\text { Mater. }\end{array}$ & $\begin{array}{l}\text { Rossane } \\
\text { Fontoura de } \\
\text { Souza. }\end{array}$ & $\begin{array}{l}\text { Implementar o contato } \\
\text { pele a pele entre mãe e } \\
\text { recém-nascido na } \\
\text { primeira hora pós parto. }\end{array}$ & $\begin{array}{l}\text { Espera-se com esta intervenção } \\
\text { capacitar e treinar } 100 \% \text { dos } \\
\text { profissionais da enfermagem que } \\
\text { atuam no centro obstétrico, } \\
\text { possibilitando uma assistência de }\end{array}$ \\
\hline
\end{tabular}




\begin{tabular}{|c|c|c|c|c|c|}
\hline & $\begin{array}{l}\text { equipe } \\
\text { enfermagem. }\end{array}$ & $\begin{array}{l}\text { Infant., } \\
\text { Recife, } 201 \\
5 .\end{array}$ & & & $\begin{array}{l}\text { enfermagem focada na real } \\
\text { necessidade do conjunto mãe- bebê. }\end{array}$ \\
\hline LILACS & $\begin{array}{l}\text { Amamentação e } \\
\text { contato pele-a-pele } \\
\text { no alívio da dor em } \\
\text { recém-nascidos na } \\
\text { vacina contra } \\
\text { Hepatite B. }\end{array}$ & $\begin{array}{l}\text { Rev. Eletr. } \\
\text { Enf. } \\
\text { [Internet], } \\
2015 .\end{array}$ & $\begin{array}{l}\text { Leite et al, } \\
2015 \text {. }\end{array}$ & $\begin{array}{l}\text { Avaliar o efeito da } \\
\text { amamentação } \\
\text { combinada ao contato } \\
\text { pele-a-pele no alívio da } \\
\text { dor dos RN submetidos } \\
\text { à vacina intramuscular } \\
\text { conta Hepatite B. }\end{array}$ & $\begin{array}{l}\text { Tanto a amamentação como o } \\
\text { contato pele-a-pele, constituem-se } \\
\text { em estratégias, sendo o alívio da } \\
\text { dor aguda em RN mais um } \\
\text { benefício que justifica a promoção } \\
\text { do uso destas medidas durante a } \\
\text { vacinação. }\end{array}$ \\
\hline SCIELO & $\begin{array}{l}\text { Amamentação, leite } \\
\text { materno e contato } \\
\text { pele a pele no alívio } \\
\text { da dor em recém- } \\
\text { nascidos submetidos } \\
\text { à punção de } \\
\text { calcâneo } \\
\text { alojamento no } \\
\text { conjunto. }\end{array}$ & $\begin{array}{l}\text { Rev. Esc. } \\
\text { Enferm, } 20 \\
16 .\end{array}$ & $\begin{array}{l}\text { Nunes et al, } \\
2016 \text {. }\end{array}$ & $\begin{array}{l}\text { Comparar as respostas } \\
\text { comportamentais e } \\
\text { fisiológicas dos recém- } \\
\text { nascidos a termo } \\
\text { amamentados com } \\
\text { aqueles que receberam } \\
\text { leite materno ordenhado. }\end{array}$ & $\begin{array}{l}\text { Métodos não farmacológicos de } \\
\text { alivio da dor no recém-nascido, é } \\
\text { importante que os profissionais de } \\
\text { saúde os conheçam para incorporá- } \\
\text { los no dia a dia do alojamento } \\
\text { conjunto. }\end{array}$ \\
\hline $\begin{array}{l}\text { GOOGLE } \\
\text { ACADÊMICO }\end{array}$ & $\begin{array}{l}\text { Contato pele a pele } \\
\text { do recém-nascido } \\
\text { com sua mãe na } \\
\text { perspectiva } \text { da } \\
\text { equipe } \\
\text { multiprofissional. }\end{array}$ & $\begin{array}{l}\text { Rev. } \\
\text { enferm. } \\
\text { UFPE } \\
\text { Recife, } \\
2017 .\end{array}$ & $\begin{array}{l}\text { Kologeski TK, } \\
\text { Strapassom } \\
\text { MR, Schneider } \\
\text { V et al. }\end{array}$ & $\begin{array}{l}\text { Conhecer a percepção } \\
\text { dos profissionais da } \\
\text { equipe multiprofissional } \\
\text { em relação ao contato } \\
\text { pele apele precoce da } \\
\text { mãe com o bebê no } \\
\text { momento do nascimento. }\end{array}$ & $\begin{array}{l}\text { O contato pele apele na sala de } \\
\text { parto constitui uma prática de } \\
\text { cuidado humanizado com forte } \\
\text { evidencia para a formação de } \\
\text { vínculo mãe/bebê. } \\
\text { Conclusão: } \\
\text { O modelo de parto e nascimento } \\
\text { vigente, constitui um importante } \\
\text { balizador nas inconformidades } \\
\text { desse processo. }\end{array}$ \\
\hline $\begin{array}{l}\text { GOOGLE } \\
\text { ACADÊMICO }\end{array}$ & $\begin{array}{l}\text { Percepção materna } \\
\text { sobre contato pele a } \\
\text { pele precoce, } \\
\text { clampeamento } \\
\text { oportuno e } \\
\text { amamentação na } \\
\text { primeira hora de } \\
\text { vida do bebê. }\end{array}$ & $\begin{array}{l}\text { Texto } \\
\text { contexto - } \\
\text { enferm, } \\
2017 .\end{array}$ & $\begin{array}{l}\text { GONÇALVES } \\
\text {, T. M. }\end{array}$ & $\begin{array}{l}\text { Analisar a percepção das } \\
\text { mães acerca do contato } \\
\text { pele a pele precoce, o } \\
\text { clampeamento oportuno } \\
\text { do cordão umbilical e a } \\
\text { primeira amamentação } \\
\text { na primeira hora de vida. }\end{array}$ & $\begin{array}{l}\text { É necessário que os profissionais de } \\
\text { saúde estejam capacitados para } \\
\text { atuarem de forma a estimular a } \\
\text { autonomia da mulher para que ela } \\
\text { participe das decisões referente à } \\
\text { sua saúde e do seu filho, de forma } \\
\text { que elas possam tomar decisões } \\
\text { conscientes e que respeitem suas } \\
\text { crenças desejos e necessidades. }\end{array}$ \\
\hline LILACS & $\begin{array}{l}\text { Contato pele a pele } \\
\text { entre mãe e recém- } \\
\text { nascido } \\
\text { amamentação na } \\
\text { primeira hora de } \\
\text { vida. }\end{array}$ & $\begin{array}{l}\text { Clin. } \\
\text { Biomed. } \\
\text { Res, } 2018 .\end{array}$ & $\begin{array}{l}\text { Abdala et al, } \\
2018 \text {. }\end{array}$ & $\begin{array}{l}\text { Analisar a prevalência } \\
\text { da CPP entre mãe e RN } \\
\text { e de amamentação na } \\
\text { primeira hora de vida. }\end{array}$ & $\begin{array}{l}\text { A equipe multiprofissional possui } \\
\text { um papel relevante na assistência à } \\
\text { mulher e ao RN, sendo responsável } \\
\text { por sensibilizar e encorajar que } \\
\text { práticas humanizadas. }\end{array}$ \\
\hline SCIELO & $\begin{array}{lr}\text { Ganho de } & \text { peso em } \\
\text { recém- } & \text { nascido } \\
\text { submetidos } & \text { ao } \\
\text { contato pele a pele. }\end{array}$ & $\begin{array}{l}\text { Rev. } \\
\text { CEFAC.20 } \\
18 .\end{array}$ & $\begin{array}{l}\text { Souza et al, } \\
2018 \text {. }\end{array}$ & $\begin{array}{l}\text { Comparar o ganho de } \\
\text { peso entre recém- } \\
\text { nascidos submetidos ao } \\
\text { método canguru e os não } \\
\text { submetidos e analisar os } \\
\text { fatores que possam } \\
\text { influenciar nesse ganho. }\end{array}$ & $\begin{array}{l}\text { Maior ganho de peso no Grupo } 1 \text {, } \\
\text { maior tempo de internação no } \\
\text { Grupo 2; diferença significante no } \\
\text { ganho de peso relacionada ao tipo } \\
\text { de dieta no Grupo } 2 \text {. Contato pele a } \\
\text { pele influencia positivamente no } \\
\text { ganho de peso e tempo de } \\
\text { internação dos neonatais. }\end{array}$ \\
\hline $\begin{array}{l}\text { GOOGLE } \\
\text { ACADÊMICO }\end{array}$ & $\begin{array}{l}\text { Atenção } \\
\text { Multidisciplinar à } \\
\text { Criança e ao } \\
\text { Adolescente. }\end{array}$ & $\begin{array}{l}\text { Revista } \\
\text { Gaúcha de } \\
\text { Enfermage } \\
\mathrm{m}, 2019 .\end{array}$ & $\begin{array}{l}\text { Silvana } \\
\text { Mendes Jung, } \\
\text { Fernanda } \\
\text { Araujo } \\
\text { Rodrigues, } \\
\text { Alessandra } \\
\text { Vaccari, } \\
\text { Silvani Herber. }\end{array}$ & $\begin{array}{l}\text { Identificar a percepção } \\
\text { materna quanto ao } \\
\text { contato pele a pele com } \\
\text { o recém-nascido } \\
\text { realizado na primeira } \\
\text { hora de vida e o } \\
\text { aleitamento materno. }\end{array}$ & $\begin{array}{l}\text { Observou-se que as puérperas } \\
\text { valorizaram o momento com o filho } \\
\text { no contato pele a pele na primeira } \\
\text { hora de vida, mesmo quando o } \\
\text { recém-nascido não sugou o seio } \\
\text { materno e/ou quando o primeiro } \\
\text { contato não tenha ocorrido com a } \\
\text { realização correta da técnica. }\end{array}$ \\
\hline GOOGLE & Contato pele a pele: & Revista & Marilin Zela et & Conhecer o papel da & A realização do contato pele a pele, \\
\hline
\end{tabular}




\begin{tabular}{|c|c|c|c|c|c|}
\hline ACADÊMICO & $\begin{array}{l}\text { Atuação da equipe } \\
\text { de enfermagem na } \\
\text { visão das puérperas. }\end{array}$ & $\begin{array}{l}\text { Multidisci } \\
\text { plinar, } \\
2019 .\end{array}$ & $\mathrm{al},$. & $\begin{array}{l}\text { equipe de enfermagem } \\
\text { na condução do contato } \\
\text { pele a pele na primeira } \\
\text { meia hora de vida do } \\
\text { recém-nascido (RN), } \\
\text { para as puérperas. }\end{array}$ & $\begin{array}{l}\text { direito da mulher, mas que } \\
\text { infelizmente a maioria desconhece, } \\
\text { as puérperas descrevem esse } \\
\text { momento como mágico, que } \\
\text { somente quem está realizando pode } \\
\text { vivenciá-lo. }\end{array}$ \\
\hline $\begin{array}{l}\text { GOOGLE } \\
\text { ACADÊMICO }\end{array}$ & $\begin{array}{l}\text { Implementação de } \\
\text { Protocolos } \\
\text { Operacional Padrão } \\
\text { Para o Contato Pele } \\
\text { a Pele Entre Mãe e } \\
\text { Recém-Nascido na } \\
\text { Primeira Hora de } \\
\text { Vida na } \\
\text { Maternidade Divino } \\
\text { Amor. }\end{array}$ & $\begin{array}{l}\text { Rev. de } \\
\text { Enfermage } \\
m \text { da } \\
\text { UFPI, } \\
2019 .\end{array}$ & $\begin{array}{l}\text { Bruna Lorena } \\
\text { de Figueiredo } \\
\text { Freire. }\end{array}$ & $\begin{array}{l}\text { Implantar um protocolo } \\
\text { operacional padrão } \\
\text { para o contato precoce } \\
\text { pele a pele entre mãe e } \\
\text { recém-nascido na } \\
\text { primeira hora. } \\
\text { Rio Grande do Norte. }\end{array}$ & $\begin{array}{l}\text { Verificou-se a efetividade da } \\
\text { capacitação executada nas oficinas } \\
\text { com o aumento significativo do } \\
\text { número de acertos dos participantes } \\
\text { no pós-teste, após exposição e } \\
\text { discussão do conteúdo para a } \\
\text { equipe de saúde. Percebeu-se total } \\
\text { de enfermagem da sala de parto. }\end{array}$ \\
\hline $\begin{array}{l}\text { GOOGLE } \\
\text { ACADÊMICO }\end{array}$ & $\begin{array}{l}\text { Fatores } \\
\text { intervenientes no } \\
\text { contato pele a pele } \\
\text { entre mãe e bebê na } \\
\text { hora dourada. }\end{array}$ & $\begin{array}{l}\text { Revista } \\
\text { Enfermage } \\
\text { m } \\
\text { Contempo } \\
\text { rânea, } \\
2019 .\end{array}$ & $\begin{array}{l}\text { RODRIGUES, } \\
\text { B. M. }\end{array}$ & $\begin{array}{l}\text { Analisar os fatores que } \\
\text { interferem no contato } \\
\text { pele a pele entre mãe e } \\
\text { bebê na hora dourada. }\end{array}$ & $\begin{array}{l}\text { Este estudo é o pioneiro devido ao } \\
\text { caráter observacional que } \\
\text { possibilito a visualização do } \\
\text { segmento d durabilidade do contato } \\
\text { pele a pele na hora dourada, como } \\
\text { também a identificação de } \\
\text { procedimentos institucionais que } \\
\text { dificultam o contato por uma hora, } \\
\text { logo após o parto. }\end{array}$ \\
\hline SCIELO & $\begin{array}{l}\text { Contato pele a pele e } \\
\text { mamada precoce: } \\
\text { Fatores associados e } \\
\text { influência no } \\
\text { aleitamento materno } \\
\text { exclusivo. }\end{array}$ & $\begin{array}{l}\text { Texto } \\
\text { Contexto } \\
\text { Enferm, } \\
2019 .\end{array}$ & Saco et al. & $\begin{array}{l}\text { Verificar os fatores } \\
\text { associados à prática do } \\
\text { contato pele a pele com } \\
\text { amamentação o na } \\
\text { primeira hora de vida e } \\
\text { sua influência no } \\
\text { aleitamento materno } \\
\text { exclusivo no primeiro } \\
\text { mês. }\end{array}$ & $\begin{array}{l}\text { Identificaram-se } 1.030 \text { prontuários, } \\
71 \text { foram excluídos e a amostra } \\
\text { final foi } 959 \text {. A prevalência do } \\
\text { contato pele a pele com } \\
\text { amamentação na primeira hora foi } \\
\text { de } 37,2 \% \text {. As boas condições de } \\
\text { nascimento da criança foram fatores } \\
\text { protetores para a realização do } \\
\text { contato pele a pele com } \\
\text { amamentação na primeira hora. }\end{array}$ \\
\hline SCIELO & $\begin{array}{l}\text { Registro de } \\
\text { enfermagem sobre o } \\
\text { contato pele a pele } \\
\text { entre mãe e recém- } \\
\text { nascido em um } \\
\text { hospital amigo da } \\
\text { criança. }\end{array}$ & $\begin{array}{l}\text { Iniciativa } \\
\text { Hospital } \\
\text { Amigo da } \\
\text { Criança, } \\
2019 .\end{array}$ & $\begin{array}{l}\text { Jéssica Strube } \\
\text { Holztrattner. }\end{array}$ & $\begin{array}{l}\text { Analisar os registros de } \\
\text { enfermagem } \\
\text { relacionados ao contato } \\
\text { pele a pele. }\end{array}$ & $\begin{array}{l}\text { Os registros de enfermagem } \\
\text { observados indicam necessidade de } \\
\text { melhorias quanto ao contato pele a } \\
\text { pele. As enfermeiras conhecem a } \\
\text { prática e entendem a importância de } \\
\text { realiza-la de maneira adequada. }\end{array}$ \\
\hline BDENF & $\begin{array}{l}\text { Compreensão da } \\
\text { enfermagem sobre o } \\
\text { contato pele a pele } \\
\text { entre mãe/bebê a } \\
\text { sala de parto. }\end{array}$ & $\begin{array}{l}\text { Rev. } \\
\text { Enferm. } \\
\text { UFSM. } \\
2020 .\end{array}$ & Souza et al. & $\begin{array}{l}\text { Descrever a } \\
\text { compreensão da equipe } \\
\text { de enfermagem da sala } \\
\text { de parto sobre o contato } \\
\text { pele a pele entre a mãe e } \\
\text { bebê na primeira hora de } \\
\text { vida. }\end{array}$ & $\begin{array}{l}\text { Os profissionais de enfermagem } \\
\text { possuem o conhecimento sobre o } \\
\text { contato pele a pele. }\end{array}$ \\
\hline BDENF & $\begin{array}{l}\text { Conhecimento dos } \\
\text { enfermeiros sobre as } \\
\text { repercussões do } \\
\text { contato pele a pele } \\
\text { em sala de parto } \\
\text { para amamentação. }\end{array}$ & $\begin{array}{l}\text { Revista } \\
\text { Eletrônica } \\
\text { Acervo } \\
\text { Saúde, } \\
2020 .\end{array}$ & $\begin{array}{l}\text { Guaraneiva de } \\
\text { Sousa Braga, } \\
\text { Célida Juliana } \\
\text { de Oliveira, } \\
\text { Edna Maria } \\
\text { Camelo } \\
\text { Chaves, Ana } \\
\text { Raquel } \\
\text { Bezerra } \\
\text { Saraiva } \\
\text { Tavares. }\end{array}$ & $\begin{array}{lr}\text { Identificar } & 0 \\
\text { conhecimento dos } \\
\text { enfermeiros acerca da } \\
\text { importância do contato } \\
\text { pele a pele, ainda em } \\
\text { sala de parto, para } \\
\text { continuação ra do } \\
\text { aleitamento materno. }\end{array}$ & $\begin{array}{l}\text { Observou-se que os enfermeiros } \\
\text { sabem a necessidade do contato } \\
\text { pele a pele para início do } \\
\text { aleitamento materno, e tentam } \\
\text { realizá-lo, para todos os partos, o } \\
\text { uso desse método de baixo custo, } \\
\text { traz benefícios incontáveis ao } \\
\text { binômio mãe e filho e, até mesmo, } \\
\text { para a sociedade. }\end{array}$ \\
\hline $\begin{array}{l}\text { GOOGLE } \\
\text { ACADÊMICO }\end{array}$ & $\begin{array}{l}\text { Contato pele a pele e } \\
\text { aleitamento } \\
\text { materno: } \\
\text { experiências de }\end{array}$ & $\begin{array}{l}\text { Revista de } \\
\text { Enfermage } \\
\mathrm{m} \text { do } \\
\text { Centro- }\end{array}$ & $\begin{array}{l}\text { Jung SM, } \\
\text { Rodrigues FA, } \\
\text { Herber S. }\end{array}$ & $\begin{array}{l}\text { Descrever as } \\
\text { experiências de } \\
\text { puérperas quanto ao } \\
\text { contato pele a pele com }\end{array}$ & $\begin{array}{l}\text { Identificou-se que a instituição } \\
\text { ainda utiliza um modelo } \\
\text { intervencionista. Dessa forma, } \\
\text { esta pesquisa foi relevante, pois }\end{array}$ \\
\hline
\end{tabular}




\begin{tabular}{|c|c|c|c|c|c|}
\hline & puérperas. & $\begin{array}{l}\text { Oeste } \\
\text { Mineir. } \\
2020 .\end{array}$ & & $\begin{array}{l}\text { o recém-nascido, } \\
\text { realizado na primeira } \\
\text { hora de vida e o início } \\
\text { do aleitamento materno. }\end{array}$ & $\begin{array}{l}\text { poderá contribuir para a reflexão } \\
\text { dos profissionais em relação aos } \\
\text { cuidados prestados ao binômio } \\
\text { mãe-bebê, possibilitando a } \\
\text { qualificação das práticas do contato } \\
\text { pele a pele e do aleitamento } \\
\text { materno na primeira hora de vida. }\end{array}$ \\
\hline SCIELO & $\begin{array}{lr}\text { Contato pele a pele: } \\
\text { conhecimento do } \\
\text { profissional } & \text { de } \\
\text { enfermagem. } & \end{array}$ & $\begin{array}{l}\text { Revista } \\
\text { Eletrônica } \\
\text { Acervo } \\
\text { Saúde,202 } \\
0 .\end{array}$ & $\begin{array}{l}\text { Lanarol et al, } \\
2020 .\end{array}$ & $\begin{array}{l}\text { Compreender } \quad \text { o } \\
\text { conhecimento do } \\
\text { trabalhador da área de } \\
\text { enfermagem em relação } \\
\text { ao contato pele a pele. }\end{array}$ & $\begin{array}{l}\text { Percebeu-se a necessidade de uma } \\
\text { reflexão aprofundada, por parte do } \\
\text { profissional da área de enfermagem, } \\
\text { sobre o contato pele a pele. }\end{array}$ \\
\hline SCIELO & $\begin{array}{l}\text { Contato pele a pele e } \\
\text { aleitamento materno } \\
\text { de recém-nascidos } \\
\text { em um hospital } \\
\text { universitário. }\end{array}$ & $\begin{array}{l}\text { Rev. } \\
\text { GaúchaEn } \\
\text { ferm. } 2020 .\end{array}$ & $\begin{array}{l}\text { Campos et al, } \\
2020 \text {. }\end{array}$ & $\begin{array}{l}\text { Determinar } \\
\text { prevalência do contato } \\
\text { pele a pele (CPP) e do } \\
\text { estímulo ao Aleitamento } \\
\text { Materno (AM). }\end{array}$ & $\begin{array}{l}\text { Uma possível limitação do estudo } \\
\text { foi não saber quanto tempo levou a } \\
\text { realização dos primeiros cuidados, } \\
\text { uma vez que esses dados foram } \\
\text { relatados pelas mulheres. }\end{array}$ \\
\hline
\end{tabular}

Fonte: Autores.

Após a leitura dos artigos selecionados, emergiu-se duas categorias: Contribuições da equipe de enfermagem para a realização do contato pele a pele e $\mathrm{O}$ contato pele a pele e a importância para a mãe e o bebê.

\section{Categoria 1. Contribuições da equipe de enfermagem para a realização do contato pele a pele.}

O conceito de atenção humanizada é amplo e possui sentidos variados. Ele envolve um conjunto de conhecimentos, práticas e atitudes voltados para a promoção do parto e do nascimento saudáveis e que priorizam o uso de procedimentos comprovadamente benéficos para a mulher e o bebê, evitando intervenções desnecessárias, de forma a preservar a privacidade e autonomia da mulher (Silva, 2015).

É de suma importância a atenção à mulher nesse momento informando-a e auxiliando-a no contato precoce e incentivando o aleitamento materno, para isso, a equipe de enfermagem precisa ser capacitada e estimulada a uma mudança de atitude profissional com a integração e valorização do binômio mãe - filho, para que as ações não sejam realizadas de forma mecanicista e sim com respeito e acolhimento (Aguiar, 2015).

Compreender as dificuldades e as facilidades pelas puérperas durante o contato pele a pele, ainda em sala de parto, implica em respeitar o desejo, a cultura e o suporte social de cada mulher que é recebida para a resolução da gestação e assistência ao puerpério imediato. A equipe de enfermagem, são os profissionais que acompanham a mulher durante todo esse período. Sendo depositada toda confiança em sua pessoa (Marlin et al., 2019).

No momento do parto e nascimento que o enfermeiro obstetra tem sua atuação imprescindível, sendo requerida tanto nesse processo como também no desenvolvimento de políticas relacionadas ao contexto obstétrico, fazendo o diferencial no cuidado prestado aos sujeitos envolvidos, de forma humana e com qualidade, promovendo experiências significativas e enriquecedoras para todos que participam (Freire, 2019).

Além disso, discussões acerca da mudança de modelo da atenção obstétrica e neonatal trouxeram a atuação da Enfermagem Obstétrica como componente da humanização do parto. No contexto de parto e nascimento, a Enfermeira Obstétrica deve ter a competência e respaldo em prestar assistência à parturiente cujo parto for normal de evolução fisiológica (sem distocia), parto de gestação de baixo risco, e seu recém-nascido saudável, considerado com boa vitalidade ao nascer, atuando em conjunto com a equipe multiprofissional se necessário (Gonçalves, 2017).

É importante que a Enfermagem, foco desta intervenção, compreenda os aspectos essenciais e necessários para atuar no cenário do parto de maneira efetiva e positiva. Ao compreender o contato pele a pele entre mãe-bebê como uma ação 
simples, barata, de fácil realização e eficaz na estabilização do recém-nascido e na formação afetiva da família, a Enfermagem passar a exercer o papel fundamental na proteção do primeiro contato (Souza, 2015).

Neste contexto, o papel desempenhado pela equipe de enfermagem é primordial, por estes profissionais prestarem assistência na sala de parto vinte e quatro horas por dia, e serem facilitadores do vínculo entre mãe e bebê na transição entre o mundo intra e extrauterino. Além disso, a proposta de humanização na assistência ao parto e nascimento preconiza que esses profissionais estimulem essa aproximação no pós-parto imediato (Souza et al., 2020).

\section{Categoria 2. $O$ contato pele a pele e a importância para a mãe e o bebê.}

A primeira hora de vida do neonato, denominada de "hora dourada", requer do profissional de saúde a identificação de riscos potenciais para a sobrevida do mesmo e a execução de práticas baseadas em evidências científicas para o cuidado adequado, dentre elas, o contato pele a pele entre mãe e bebê, o qual atua como uma terapêutica recomendada (Monteiro, 2019).

Após o nascimento do bebê é importante garantir o contato pele a pele sem interrupções e sem pressa entre toda a mãe e seu bebê saudável, livre de cobertas ou roupas. O contato pele a pele acalma a mãe e o bebê ajudando a estabilizar o batimento cardíaco e a respiração do bebê, mantém o bebê aquecido com o calor do corpo da mãe, auxilia a adaptação metabólica e a estabilização da glicose sanguínea do bebê, reduz o choro do bebê, reduzindo também o estresse e o gasto de energia (Marlin et al., 2019).

Durante as primeiras horas de vida os recém-nascidos $(\mathrm{RN})$ sofrem várias alterações fisiológicas para se adaptarem a um ambiente aéreo, além de depararem- se com um ambiente iluminado, ruidoso, com odores diferentes e com perda do limite físico intrauterino. Somando-se a esses fatores estão as rotinas pós- nascimento, em que os RN, em um curto período de tempo, são submetidos a procedimentos estressantes e, muitas vezes, dolorosos (Leite et al., 2015).

Considera-se fundamental que o RN não seja separado de sua mãe ao nascer, exceto por razões clínicas significativas, devendo ser colocado em CPP o mais precoce possível após o nascimento para melhor conduzir seu processo de adaptação ao meio extrauterino e de autorregulação dos sinais vitais (Abdala et al., 2018).

O momento do nascimento é primordial para a formação do vínculo, já que mantê-los juntos logo após o parto estimula no recém-nascido mecanismos fisiológicos, sensoriais e comportamentais, além de proporcionar aumento do aleitamento materno exclusivo, diminuição da mortalidade infantil e menor incidência de maus-tratos e abandono das crianças (Freire, 2019).

$\mathrm{O}$ contato pele a pele precoce na sala de parto é uma prática de atendimento humanizado. A partir desse olhar, o recém-nascido necessita de suporte para adaptar-se à vida extrauterina. Por isso, torna-se necessário que o local do nascimento seja um ambiente acolhedor, silencioso, com manutenção de temperatura ideal e que ocorra a realização do contato epidérmico precoce entre mãe e bebê. A interação imediata, por meio do toque pele a pele, é um momento instintivo sublime dotado de significados e benefícios para a mãe e o bebê (Kologeski et al., 2017).

Dessa forma, exceto por alterações clínicas significativas, considera-se essencial que o RN não seja separado de sua mãe, após o nascimento, devendo ser colocado, precocemente, em contato pele a pele para facilitar seu processo de vitais. Portanto, recomenda-se que o contato pele a pele seja implementado como rotina hospitalar, tornando-a viável para a maioria das puérperas, inclusive em países em desenvolvimento, visto que se trata de uma estratégia de baixo custo (Jung \& Rodrigues, 2020).

\section{Considerações Finais}


Com este estudo, foi possível observar que o contato pele a pele tem como uma ação que lhe proporciona a oportunidade de amar, se sentir mãe, aquela que cuida e protege seu filho. A maioria das mães acredita que a prática permite que ela possa olhar, tocar seu filho, ver que ele é saudável e que está bem. O contato pele a pele precoce foi percebido também como uma experiência nova de exercer o papel fundamental no parto e nascimento, e na realização dos cuidados prestados à mãe e ao recém-nascido.

Mediante a isto, a enfermagem tem grande contribuição e influencia, pois, são essenciais para que seja estimulado o contato precoce entre a mãe e o bebê, podendo agir como facilitadores desses processos, e visto que a equipe de enfermagem exerce também o papel fundamental no parto e nascimento e na realização dos cuidados prestados à mãe e ao RN.

Faz-se necessário que tenham novos estudos sobre este tema, pois é primordial para que a perpetuação desta prática seja amplificada, bem como esta seja incorporada em todos os serviços de saúde, independente da via de parto.

Sugerimos a ampliação deste estudo, visando maior divulgação para a população sobre esta prática, sendo realizadas oficinas, salas de espera, orientações durante o pré-natal e capacitações aos profissionais de enfermagem que atuam com gestantes e puérperas.

\section{Referências}

Abdala, L. G. \& Cunha, M. L. C. D. (2018). Contato pele a pele entre mãe e recém-nascido e amamentação na primeira hora de vida. Clinical and biomedical research. 38 (4), 356-60.

Aguiar, R. S. (2015). Contribuições da enfermagem para o contato pele a pele entre o binômio mãe-filho. Universidade Federal de Minas Gerais, 32(19): 18-43.

Almeida, O. S. C., Gama, E. R. \& Bahiana, P. M. (2015). Humanização do parto: a atuação dos enfermeiros. Revista Enfermagem Contemporânea, 4(1): 23173378 .

Fassarella, B. P. A., Maled, M., Ribeiro, W. A., Pimenta, E. S. S., Conềa, M. C. B., Pinheiro, D. S. \& Peixoto, M. S. B. E. (2018). Percepção da equipe de enfermagem frente. Revista Nursing, 21(246), 2489-2493.

Freire, B. L. D. F. (2019). Implantação de protocolo operacional padrão para o contato pele a pele entre mãe e recém-nascido na primeira hora de vida na Maternidade Divino Amor. Rev. de Enfermagem da UFPI, 5(4), 75.

Gil, A. C. (2019). Como elaborar projetos de pesquisa. São Paulo: Editoras Atlas, 2 (26), 1982-1662.

Gonçalves, A. D. C., Rocha, C. M. D., Gouveia, H. G., Armellini, C. J., Moretto, V. L. \& Moraes, B. A. (2015). O acompanhante no centro obstétrico de um hospital universitário do sul do Brasil. Revista gaúcha de enfermagem, 36 (1), 159-167.

Paula, G. T. (2017). Percepção materna sobre contato pele a pele precoce, clampeamento oportuno e amamentação na primeira hora de vida do bebê. Universidade Federal de Minas Gerais. 33(6), 361-281.

Jung, S. M., Rodrigues, F. A. \& Herber, S. (2020). Contato pele a pele e aleitamento materno: experiências de puérperas. Revista de Enfermagem do CentroOeste Mineiro, 10, 2236-6091.

Kologeski, T. K., Strapasson, M. R., Schneider, V. \& Renosto, J. M. (2017). Contato pele a pele do recém-nascido com sua mãe na perspectiva da equipe multiprofissional. Rev. Enferm, 11(1), 94-101.

Köche, J. C. (2016). Fundamentos de metodologia científica. Trabalho de conclusão de curso (TCC). Editora Vozes.

Leite, A. M., Castral, T. C., Nascimento, L. C., de Sousa, M. I. \& Scochi, C. G. S. (2015). Amamentação e contato pele-a-pele no alívio da dor em recémnascidos na vacina contra hepatite B. Revista Eletrônica de Enfermagem, 17(3), 319-32.

Marlin, Z., Jossane, D. S. D. S. \& Stella, M. D. O. (2019). Contato pele a pele: Atuação da equipe de enfermagem na visão das puérperas. Revista Multidisciplinar. 10(2), 2595-8402.

Monteiro, B. R. (2019). Fatores intervenientes no contato pele a pele entre mãe e bebê na hora dourada. Dissertação de Mestrado, Universidade Federal do Rio Grande do Norte.

Silva, C. M., Pereira, S. C. L., Passos, I. R. \& Santos, L. C. D. (2016). Fatores associados ao contato pele a pele entre mãe/filho e amamentação na sala de parto. Revista de Nutrição, 29 (3), 457-471.

Silva, M. K. A. (2018). Expectativas e frustrações vivenciadas por mulheres que optam pelo parto normal. Universidade Federal de Campina Grande, 51(2), 777-780.

Silva, L. M. F. F., Barbosa, P. A., de Olivindo, D. D. F. \& de Lima Ximenes, V. (2016). Promoção do aleitamento materno na primeira hora de vida do recémnascido por profissionais da enfermagem. Arquivos de Ciências da Saúde da UNIPAR, 20(2), 137-143. 
Research, Society and Development, v. 11, n. 2, e6711225467, 2022

(CC BY 4.0) | ISSN 2525-3409 | DOI: http://dx.doi.org/10.33448/rsd-v11i2.25467

Souza, H. L. R., Fernandes, F. E. C. V., de França Pereira, R. C. L. \& de Melo, R. A. (2020). Compreensão da enfermagem sobre o contato pele a pele entre mãe/bebê na sala de parto. Revista de Enfermagem da UFSM, 10(19), 2179-7692.

Souza, R. F. (2015). Fortalecendo o vínculo mãe-filho por meio do contato pele a pele: uma intervenção junto à equipe de enfermagem. Universidade Federal de Minas Gerais. 37, 324-89. 